\title{
PRINTED MEDIA, HYPERTEXT AND CHATTERBOTS IN LEARNING
}

\author{
A Comparative Study
}

Maria José Carvalho De Souza Domingues ${ }^{1}$ and Raul Sidnei Wazlawick ${ }^{2}$

${ }^{1}$ Regional University of Blumenau, ${ }^{2}$ Federal University of Santa Catarina

\begin{abstract}
This paper compares the influence of printed media, hypertext and chatterbots in the learning process of undergraduate business students. It has been found that chatterbots provide better results in terms of learning, especially in regard to the students' ability to answer discursive questions. The conclusion is that a chatterbot is more effective than hypertext and printed media for educational purposes.
\end{abstract}

Keywords: Chatterbots, Hypermedia, Learning systems.

\section{INTRODUCTION}

While the use of Information and Communications Technology (ICT) in Education is largely supported by hypertext and its variants, such as the Internet, there has been little work done about the application of chatterbots to learning situations (Laven, 2000; Primo, 2000). Chatterbots are programs that are able to simulate conversation with a human partner. Chatterbots are widely used in entertainment web sites and for e-commerce. We believe that chatterbots can also be useful for educational purposes. The understanding of information presentation and recuperation process that underpin the operation of chatterbots in different types of media can help in the learning process. The main purpose of this work is to verify the effectiveness of chatterbots in the learning process of undergraduate business students.

According to Laven (2000) and Leaverton (2000), chatterbots are computer programs that use artificial intelligence to simulate dialogues with users. Faqbots are chatterbots designed to answer simple and frequent questions about their Frequently Asked Questions (FAQ) database (Laven, 
2000). These kinds of chatterbots are found in many e-commerce sites. Examples of Faqbots are LuciMcBot and Roy (http://www.artificiallife.com), Nicole (http://an1-sj.nativeminds.com/home.html) and Linda (http://www.extempo.com).

When using chatterbots in learning, the idea is that the students would have complementary material to work with that they could use in conjunction with a chatterbot when the teacher is absent. Little research has been done in this area. Most of the previous works report using chatterbots as intelligent tutors that propose questions and direct the dialogue with the students (Graesser et. al., 1999).

\section{HYPOTHESES}

When using chatterbots, students assume an active role in the learning process; a different role from those they often adopt when using hypertext and printed media,. In this case they need to formulate questions and not only read information prepared by others. It helps them to assign meaning to the information and relate it to previous knowledge. It leads to our first hypothesis.

\subsubsection{Hypothesis 1}

The use of chatterbots will improve the quality of learning compared to the use of hypertext and printed media. However, chatterbots present a limitation when compared to hypertext. In hypertext systems, the information is easily accessed by navigation. The chatterbot requires that the user formulate a question in order to give access to the stored information. If the right questions were not asked, the information remains hidden of the user. Therefore, we believe that students using chatterbots will recover less information than students using a hypertext. However, because of the way the information is accessed in the chatterbot, we also believe that the information retrieved will be better understood and retained by the student. It leads to our second hypothesis:

\subsubsection{Hypothesis 2}

Although a chatterbot user retrieves less information than a hypertext user, the information retrieved is better interpreted and retained. 


\section{METHODOLOGY}

Some problems on using chatterbots in learning environments are discussed by Primo (2000):

- The technology has inherent limitations.

- The dialogues are predefined in a certain way.

- When the designer defines the questions (or keywords) and appropriate answers, he/she defines the scope of what can be asked to the chatterbot.

- Questions out of the scope would not have an answer associated, and should lead to an evasive answer, or to a suggestion to change the subject.

- Another difficulty that students may consume time trying to find answers that do not exist in the database.

The solution to cope with those situations is to produce chatterbots with very strict and delimited scope. This can significantly reduce the number of problems reported.

Another problem identified by Chen and Rada (1996) in research comparing hypertexts is that the diversity of chatterbot design makes it hard to develop effective criteria comparison among different systems. In order to avoid that problem, we chose an experimental design that allowed the comparison between hypertext and chatterbot. The solution was to develop both the hypertext and chatterbot from the same initial text, which consisted of a number of questions and answers. Then the hypertext was structured as a FAQ and the chatterbot in its equivalent FaqBot. Both have the same repertoire of questions and the same answers. The only difference between the chatterbot and the hypertext is that the hypertext shows the list of questions with a link to the answers, and the chatterbot shows only an entry line where the user has to type free questions.

In order to have a very well delimited scope, a management situation (a case study) was presented to a group of students. They were solicited to ask some questions in order to solve the problem proposed. It was possible to collect more than 500 questions from that group of students. After that, equivalent questions were grouped, and the answers added to the FAQ database.

To evaluate the performance of each studied media (printed media, hypertext and chatterbot), a group of 56 students was divided into 3 subgroups, one for each kind of media. Each group read the case study and interacted with only one kind of media (containing the FAQ database) in order to solve a proposed problem. After that, each student was evaluated by a discursive test with 4 questions and a multiple-choice test with 10 questions. The discursive questions were evaluated by comparison to default answers. 


\section{ANALYSIS AND INTERPRETATION}

Figure 1 analyses the students' grades in discursive questions, and shows that the chatterbot group has smaller amplitude and a higher median in grades. Students in that group were more assertive than the others. Students that used hypertext and printed media had more dispersed grades.

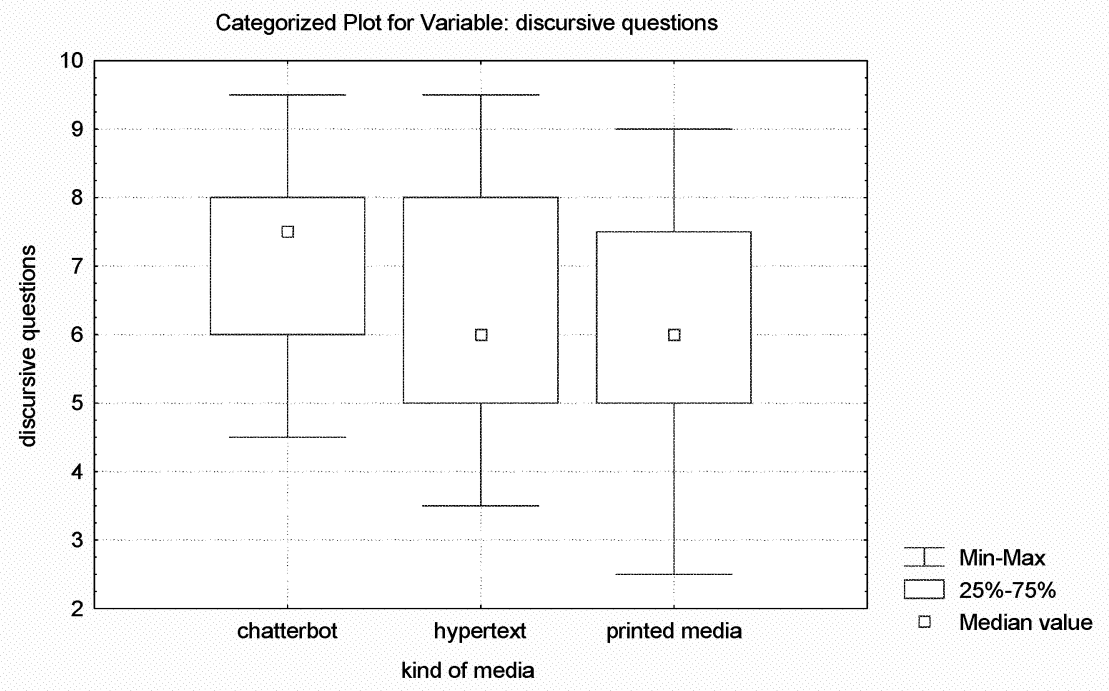

Figure 1. Box-plot for the grades in discursive questions.

Figure 2 analyses the grades obtained in multiple-choice questions. The grades obtained by the chatterbot group concentrate around the median. The hypertext group presents a greater dispersion of the grades. The printed media group shows great concentration of grades higher than 7 .

The ANOVA test (Table 1) shows that the chatterbot has a significant result for discursive questions. When considering the information effectively retrieved, the chatterbot also has a significant result for multiple-choice questions. 


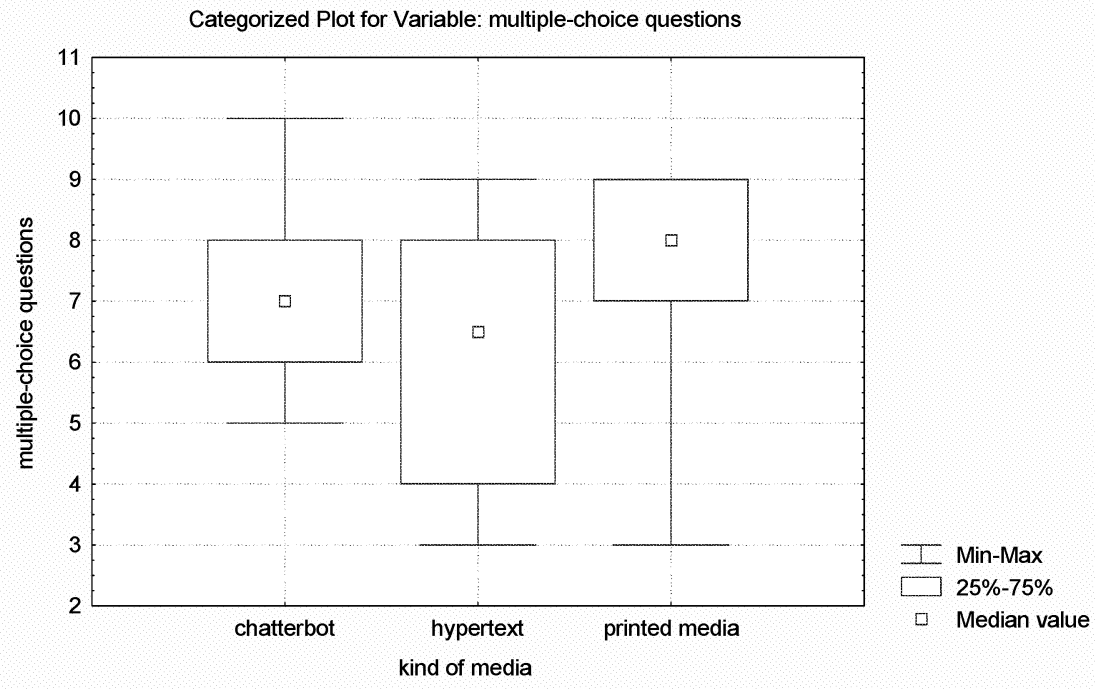

Figure 2. Box-plot for the grade in the multiple-choice questions.

Categorized Plot for Variable: multiple-choice questions/information accessed

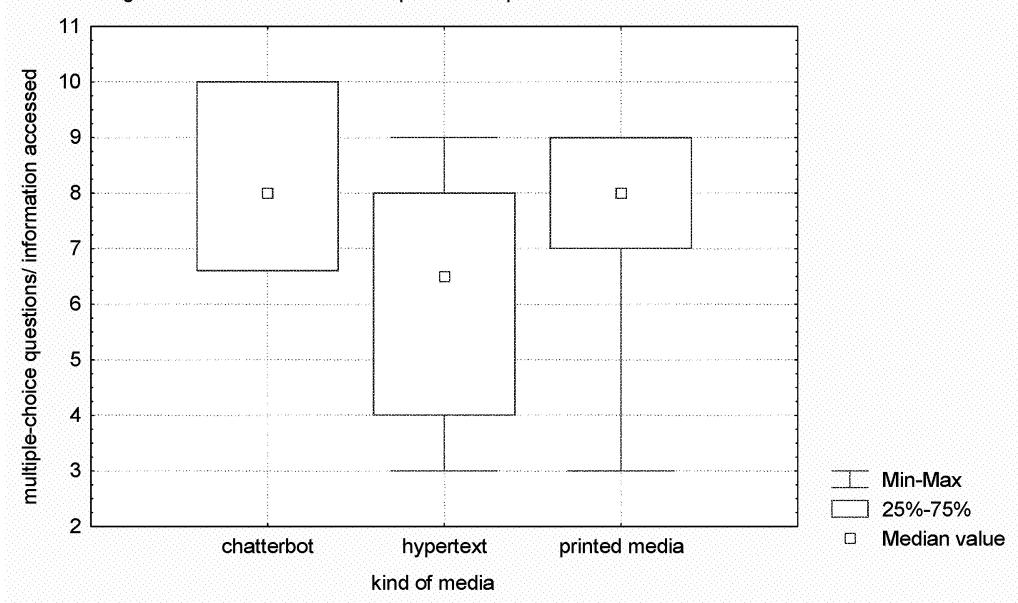

Figure 3. Box-plot for students grades in the multiple-choice questions considering only the information accessed. 
Table 1. ANOVA results for chatterbot

\begin{tabular}{llll}
\hline & Discursive Questions & $\begin{array}{l}\text { Multiple-Choice } \\
\text { Questions }\end{array}$ & $\begin{array}{l}\text { Multiple-Choice } \\
\text { With Effectively } \\
\text { Retrieved } \\
\text { Information }\end{array}$ \\
\hline Chatterbot & 0.005 & 0.715 & 0.006 \\
\hline
\end{tabular}

The Contrast Test was used in order to verify if the differences were statistically valid. According to Montgomery (1997), the Contrast Test is the best method for multiple comparisons between means. In this test the hypothesis are verified through linear combinations among the treatments. Table 2 summarizes the values obtained for the means.

Table 2. Summary of students' mean scores

\begin{tabular}{llll}
\hline & $\begin{array}{l}\text { Printed } \\
\text { media }\end{array}$ & Hypertext & Chatterbot \\
\hline Discursive & 5.452 & 6.197 & 7.366 \\
Multiple-choice & 6.717 & 6.395 & 6.772 \\
Objective considering the accesses & 6.717 & 6.395 & 8.246 \\
\hline
\end{tabular}

The Contrast Test (Table 3) shows that the utilization of chatterbots increase the possibility of learning when compared to hypertext and printed media when discursive questions and retrieved information is considered.

Table 3. Contrast Test results for chatterbot, hypertext and printed media.

\begin{tabular}{lll}
\hline Test & Discursive questions & Retrieved information \\
\hline Chatterbot $x$ Hypertext & 0.012 & 0.001 \\
Chatterbot $x$ Printed Media & 0.000 & 0.010 \\
\hline
\end{tabular}

\section{CONCLUSIONS}

The experiment confirmed hypotheses 1 and 2. The use of a chatterbot improves the quality of learning when compared to hypertext and printed media. Even if students retrieve less information, they retain and interpret the information in a more useful way when using the chatterbot. It was verified that students using the chatterbot provided more consistent and elaborated answers.

The experiment verified also that students had some difficulty in asking questions of the chatterbot. All of the students had 40 minutes to interact with the assigned media, and in the case of the chatterbot group, the time for 
formulation of the first question averaged 7.61 minutes. Each pair of students asked an average of 16 questions in 40 minutes.

We believe that the small number of questions influenced the outcomes of the multiple-choice testing, given that the chatterbot group has relatively less information retrieved than the other two groups. However, it was observed that the process of thinking about the questions to ask to the chatterbot gave the students the ability to perform better in the discursive test.

\section{REFERENCES}

Chen, C., \& Rada, R. (1996). Interacting with hypertext: A meta-analysis of experimental studies. Human-Computer Interaction, 11(2), 125-156.

Graesser, A. C., Wiemar-Hastings, K., Wiemar-Hastings, P., \& Kreuz, R. (1999). Autotutor: a simulation of a human tutor. Journal of Cognitive Systems Research. 1, 35-51.

Laven, Simon. (1996). The Simon Lavel Home Page. Retrieved from http://www.toptown.com/hp/sjlaven/

Leaverton, Michael. How Virtual Agents Make the Web More Human. in CNET TechTrends. Retrieved from http://www.cnet.com/techtrends/0-1544320-8-2862007-1.html

Montgomery, D. C. (1997). Design and analysis of experiments. $\left(4^{\text {th }}\right.$ ed.), New York: Wiley.

Primo, A. F. T. (n.d.) Chatterbots: Robôs de conversação. Retrieved from http://www.cybelle.cjb.net

\section{BIOGRAPHY}

Raul Sidnei Wazlawick received his Bachelor in Computer Science in 1988 and is a Doctor in Engineering (1993). He is an associate professor at the Federal University of Santa Catarina and Director of the Graduate Program on Computer Science. He is also a member of the Council of the Brazilian Computer Society and is the national representative of his country on IFIP's Technical Committee 3 (Education).

Maria José Carvalho de Souza Domingues received her Bachelor in Business Administration in 1986 and her Doctor in Industrial Engineering in 2003. She is an associate professor at the Regional University of Blumenau and Director of the Graduate Program in Business Administration. 